\title{
UMA ABORDAGEM DE CONCEITOS ELEMENTARES DE GEOMETRIA NÃO EUCLIDIANA: UMA EXPERIÊNCIA VIVENCIADA NO ENSINO DE MATEMÁTICA A PARTIR DE UMA SEQUÊNCIA DIDÁTICA
}

\author{
W. P. BRUM ${ }^{1}$ e E. SCHUHMACHER ${ }^{2}$ \\ ${ }^{1}$ Universidade Regional de Blumenau - ufsc2013@yahoo@com.br \\ ${ }^{2}$ Universidade Regional de Blumenau - elcio@furb.br
}

Artigo submetido em setembro/2013 e aceito em fevereiro/2014

\begin{abstract}
RESUMO
Neste artigo apresentamos um relato de uma experiência, de caráter qualitativo, a qual teve como objetivo analisar a utilização de diferentes atividades, por meio de uma sequência didática para o ensino de Geometria não Euclidiana, em particular, Esférica e Hiperbólica. Para isso, realizamos uma pesquisa participante com 14 estudantes da 2a série do Ensino Médio de uma escola da rede pública de Tijucas, Santa Catarina. A pesquisa baseou-se na Teoria da Aprendizagem Significativa de Ausubel. A pesquisa foi
\end{abstract}

dividida em três momentos: no primeiro foi aplicado um pré-teste, no segundo momento ocorreu a aplicação da sequência didática e, por fim, foi aplicado um pós-teste. Os resultados evidenciam que, após a sequência didática, grande parte dos estudantes conseguiu assimilar, diferenciar e reconciliar conceitos de Geometria Euclidiana, Esférica e Hiperbólica. Por ser um tema ainda novo nos bancos escolares, houve estudantes que permaneceram com um posicionamento euclidiano frente ao problema não euclidiano.

PALAVRAS-CHAVE: Geometria não Euclidiana, Aprendizagem Significativa, Sequência didática.

\section{AN APPROACH TO BASIC CONCEPTS OF NON-EUCLIDEAN GEOMETRY: AN EXPERIENCE IN TEACHING OF MATHEMATICS EXPERIENCED FROM A DIDACTIC SEQUENCE}

\begin{abstract}
In this paper we present a report of an experience with a qualitative character, which aimed to examine the use of different activities through a didactic sequence for teaching non-Euclidean geometry, in particular Spherical and Hyperbolic. To this end, we conducted a participatory research with 14 students of the 2 nd year of High School in a public school of Tijucas, Santa Catarina. The research relied upon the Theory of Meaningful Learning by Ausubel. The research was divided into three phases: in the first one, a pretest was
\end{abstract}

applied, in the second moment, it occurred the implementation of the didactic sequence, and finally a post-test was applied. The results show that, after the didactic sequence, most students were able to assimilate, differentiate and reconcile concepts of Euclidean, Spherical and Hyperbolic Geometry. For it still is a new subject in school databanks, there were students who remained with a Euclidean positioning facing a non-Euclidean problem.

KEYWORDS: Non-Euclidean Geometry, Meaningful Learning, Didactic Sequence. 


\section{INTRODUÇÃO}

O presente artigo tem como objetivo central apresentar um relato parcial dos resultados da pesquisa Abordagem de Conceitos de Geometria Esférica e Hiperbólica no Ensino Médio Usando Uma Sequência Didática, desenvolvida como dissertação de mestrado, no Programa de Pós Graduação em Ensino de Ciências Naturais e Matemática, área de concentração Didática da Matemática, realizada na Universidade Regional de Blumenau, Santa Catarina e concluída no ano de 2013.

Tradicionalmente, os conhecimentos geométricos abordados em sala de aula se restringem às relações lógicas e construções de símbolos advindos de uma Geometria dedutiva e axiomática, estabelecida na Grécia há cerca de 2700 anos e conhecida hoje como Geometria Euclidiana. No entanto, ao observar a superfície terrestre com sua forma elipsoidal, as montanhas, as ondas do mar e tantos outros objetos encontrados na natureza, evidenciam-se as dificuldades de construir alguns conceitos no campo da Geometria sustentados por noções primitivas como de reta, ponto e plano.

Nas duas últimas décadas, houve uma intensa discussão nos meios educacionais por parte dos membros de associações de profissionais da Matemática, como Kalleff (2004), Cabariti (2006), Alves (2008), Bongiovani (2010), Carvalho (2011), Cedrez (2012), Leivas (2012) e Martos (2012) para a inclusão de conteúdos advindos da Geometria Euclidiana, como a Geometria Esférica e Hiperbólica nos bancos escolares, considerada como adequado à formação de estudantes para o século XXI em decorrência dos avanços teóricos da Matemática e da Computação.

Dessas discussões emergiram alguns questionamentos: o ensino da Geometria não Euclidiana é um tema distante da realidade dos estudantes? O modelo geométrico para representar o planeta Terra abordado nas aulas de Geografia e Matemática é um plano, uma folha retangular ou uma superfície quase esférica? Se um dos pontos de discussão é a reformulação do ensino no Brasil, porque as Geometrias não Euclidianas ainda não são consideradas um ramo importante da Matemática por parte dos professores? Será que o ensino de Geometrias não Euclidianas, como a Esférica e Hiperbólica vem causando inquietações em professores de Matemática por ser um assunto novo e ainda desconhecido?

A busca de respostas para estas questões revela além de sua importância, a necessidade de divulgação junto aos professores desse conteúdo ainda pouco explorado em sala de aula, afinal, nos dias atuais, naves espaciais, por exemplo, percorrem em suas viagens trajetórias que não são retilíneas e no passado, segundo Eves (2008), Boyer (2009) e Mlodinow (2010) existem registros que indicam o medo de alguns navegadores por acreditarem que ao fim do horizonte, navios eram engolidos ou chegaria ao "fim do mundo". Este pensamento era devido à interpretação que muitas pessoas atribuíam ao formato da Terra.

A Geometria é um dos temas mais interessantes para ser explorada pelos professores, por se constituir de uma riqueza em ilustrações, por possibilitar resoluções diversas com criatividade, e por fim, proporcionar aos estudantes uma interação mais dinâmica com o conhecimento. Uma das justificativas para esta afirmação é a existência de discussões acerca da inserção de Geometria Esférica e Hiperbólica nos currículos escolares que se encontram nos Parâmetros 
Curriculares Nacionais de Matemática (BRASIL, 1998), os quais apresentam a importância do ensino de outras geometrias aos estudantes:

[...] a Matemática não evolui de forma linear e logicamente organizada. Desenvolve - se com movimentos de idas e vindas, com rupturas de paradigmas. Frequentemente um conhecimento é amplamente utilizado na ciência ou na tecnologia antes de ser incorporado a um dos sistemas lógicos formais do corpo da Matemática. Exemplos desse fato podem ser encontrados no surgimento dos números negativos, irracionais e imaginários. Uma instância importante de mudança de paradigma ocorreu quando se superou a visão de uma única geometria do real, a Geometria Euclidiana, para aceitação de uma pluralidade de modelos geométricos, logicamente consistentes, que podem modelar a realidade do espaço físico. (BRASIL, 1998, p. 24, grifo nosso).

Neste sentido, os PCN (Parâmetros Curriculares Nacionais) colocam que entre os objetivos do ensino de Matemática, se encontra o desenvolvimento do pensamento geométrico. Recomenda-se a exploração de situações de aprendizagem que levem o estudante a resolver situações problema de localização e deslocamento de pontos no espaço, ler mapas, estimar e comparar distâncias percorridas, reconhecer propriedades de formas geométricas e saber usar diferentes unidades de medida. Portanto, há uma orientação para situações de aprendizagem que levem o estudante a estabelecer diferenças entre objetos sob diferentes pontos de vista, construindo e interpretando suas representações.

Para estabelecer diferenças entre objetos geométricos, conforme orienta os PCN, é preciso identificar uma pluralidade de modelos geométricos na natureza que pode ser pelo estudo das navegações, no sistema de localização por GPS (Sistema de Posicionamento Global), em aulas de Geografia ao tratar sobre o planeta Terra, na Física para compreensão do comportamento da luz no espaço, em objetos comuns do nosso cotidiano, como trompetes, batatas enlatadas, cornetas, ondas do mar, poltronas, garrafas de vinhos e outros que transitam nas diversas áreas do conhecimento.

Apesar de sua reconhecida importância porque a Geometria é deixada em segundo plano ou até muitas vezes é desprezada pelos professores? Uma possível resposta entre muitas razões, está na promulgação da primeira LDB (Lei de Diretrizes e Bases do Ensino) de 1ำ e 20 Graus em 1971, que possibilitou a cada professor elaborar seu programa de acordo com as necessidades dos estudantes. É possível que uma formação inicial deficitária de diversos professores acerca dos conhecimentos de Geometria Esférica e Hiperbólica também seja um indicativo para ausência deste tema em sala de aula.

O fato é que muitos professores se tornaram dependentes dos livros didáticos, em que estes enfatizam conteúdos algébricos em detrimento dos conhecimentos geométricos. Para Vogelmann (2011), a maioria dos professores e os livros didáticos formam um pano de fundo para a Aritmética e a Álgebra, deixando a Geometria em segundo plano. Diante dessa realidade e encontradas algumas pesquisas sobre Geometria Esférica e Hiperbólica evidenciando a problemática, surgiu a seguinte pergunta problema da referente pesquisa: Como explorar os conceitos de Geometria Esférica e Hiperbólica no Ensino Médio, a fim de desenvolver a compreensão nos estudantes para a pluralidade de modelos geométricos no espaço em que vivem? 
Para responder a pergunta acima e atender ao objetivo da pesquisa adotamos como recurso a composição de uma sequência didática abordando temas de Geometria Euclidiana, Esférica e Hiperbólica.

\section{A GEOMETRIA ESFÉRICA E HIPERBÓLICA}

Durante o século XVII, a busca pela redução do 5o postulado a um teorema foi conduzida até o século XIX, quando a Geometria de Euclides já não respondia aos novos conhecimentos da Matemática, emergindo assim outras geometrias, fundamentadas e embasadas teoricamente com conceitos apoiados nos quatros primeiros postulados de Euclides, apenas discordando do postulado das paralelas (STRUIK, 1997). O surgimento das Geometrias não Euclidianas no século XIX foi um marco histórico no rumo da Matemática, tendo como precursor, lembra Boyer (2009), Karl Friedrich Gauss (1777-1855). Este gênio seria considerado um dos maiores matemáticos com profunda influência em muitas áreas da Matemática. Gauss suspeitava que o 5o postulado pudesse ser um teorema e entre 1813 a 1816, finalmente confirmou sua hipótese, resultado tanto aguardado desde Euclides. Desenvolveu equações para um triângulo no espaço não euclidiano, conhecido como Geometria Hiperbólica. No entanto, não revelou seus estudos para a comunidade científica, comenta Coutinho (2001) e não era a igreja seu maior temor, mas os filósofos, com destaque a Immanuel Kant que viera a morrer em 1804.

Embora Gauss não tivesse revelado suas descobertas, dois outros matemáticos conhecidos por ele fizeram concomitantemente: o húngaro Johann (Janos) Bolyai, e o russo Nicolai Lobachevsky. Os trabalhos de Lobachevsky colocaram em dúvida a Geometria de Euclides. Mlodinow (2010) conta que em 1867, os artigos desses dois matemáticos foram incluídos no livro Elementos de Matemática de Heinrich Richard Baltzer (1818-1887) e se tornou referência entre os que trabalham com geometrias alternativas. Para encerrar a busca da prova para o 50 postulado, o matemático italiano Eugênio Beltrami (1835-1900) demonstrou que se a Geometria de Euclides forma uma estrutura consistente, então o mesmo deve ocorrer com os espaços não euclidianos. Os resultados de Lobachevsky abalaram as estruturas da comunidade científica, sofrendo duras críticas por parte de alguns filósofos como Kant e Hegel no século XIX acerca dessa descoberta, mas foi somente com os trabalhos de Einstein na era relativística que a Geometria Esférica e Hiperbólica ganhou papel fundamental no mundo científico e lugar de destaque na história da Matemática.

Os avanços da Geometria Esférica, segundo Mlodinow (2010), Eves (2008), Boyer (2009) se devem aos trabalhos do alemão Georg Friedrich Bernhard Riemann. Na tentativa de demonstrar o 5o postulado de Euclides, Riemann abriu um universo para novos estudos afirmando que se a infinitude de retas fosse descartada, então com alguns ajustes nos demais postulados outra Geometria se desenvolveria, a Esférica, conforme figura 12. De acordo com Mlodinow (2010), Riemann afirmava que o plano é a superfície de uma esfera e uma reta é interpretada como o círculo máximo.

Neste tipo de espaço, Riemann aponta situações diferentes com relação a Geometria Euclidiana. Entre as situações, os autores citam que a soma dos ângulos de um triângulo construído sobre a superfície esférica é maior do que dois retos e que neste sistema geométrico não existem retas paralelas. Segundo Courant e Robbins (2000), a Geometria Esférica colocou em xeque o sistema geométrico de Euclides. Se Riemann não tivesse incluído a Geometria Esférica na 
sua lista de interesses, o instrumento matemático que Einstein precisou para explicar a teoria da relatividade possivelmente não teria existido. $O$ tímido e frágil gênio ao contrair pleurisia, morreu de tuberculose antes de completar 40 anos na cidade de Selasca, na Itália em 1859.

Os avanços da Geometria Hiperbólica se devem a Nicolai Ivanovich Lobachevsky. Lobachevsky se tornou professor na Universidade de Kazan, cargo que ocupou até ao fim da vida. Em meados do século XIX, Lobachevsky publicou o artigo à Sociedade de Física e Matemática na cidade de Kazan intitulado "Princípios de Geometria" sem nenhuma aceitação. Concomitantemente aos trabalhos de Lobachevsky, Janos Bolyai envia uma carta ao seu pai, Farkas Bolyai, no qual relata as descobertas maravilhosas de um universo criado por ele, deixando mais de 2000 páginas de manuscritos sobre Matemática.

Bolyai não demonstrou nenhuma indecisão nas suas afirmações, mas não aprofundou suas ideias como fez o russo Lobachevsky em suas publicações, e por isso, a geometria de Lobachevsky é conhecida por Geometria Hiperbólica (COUTINHO, 2001). O que é a Geometria Hiperbólica? Segundo Mlodinow (2010) é o espaço resultante da substituição do postulado das paralelas de Euclides pela suposição de que, para qualquer reta não existe apenas uma, mas infinitas retas paralelas a partir de qualquer ponto. Em sua obra intitulada Pangeometria de 1855, Lobachevsky apresenta dois pontos importantes acerca da Geometria Hiperbólica. O primeiro, trata da soma das medidas dos ângulos internos de um triângulo ser menor do que 180 ํ e o segundo, é que triângulos semelhantes não existem neste tipo de superfície.

\section{ALGUNS ASPECTOS DA TEORIA DA APRENDIZAGEM SIGNIFICATIVA}

A teoria da aprendizagem significativa foi formulada inicialmente pelo psicólogo norte americano David Paul Ausubel. As ideias de Ausubel, cujas formulações iniciais são dos anos 60, se encontram entre as primeiras propostas psicoeducativas em sua obra "Psicologia Educacional", recebendo colaborações em 1980 de Joseph Donald Novak e Helen Hanesian, acerca de fatores sociais, cognitivos e afetivos na aprendizagem.

[...] é essencial levar-se em consideração as complexidades provenientes da situação de classe de aula, estes por sua vez, incluem a presença de muitos alunos de motivação, prontidão e aptidões desiguais; as dificuldades de comunicação entre professor e aluno; as características particulares de cada disciplina que esta sendo ensinada; e as características das idades dos alunos (AUSUBEL; NOVAK; HANESIAN, 1980, p. 5).

Para os autores, basicamente, a ideia central de aprendizagem significativa é uma reorganização clara da estrutura cognitiva, isto é, um processo pelo qual uma nova informação se relaciona com um aspecto relevante na estrutura do conhecimento do estudante. A aprendizagem significativa é uma tentativa de fornecer sentido ou estabelecer relações de modo não arbitrário e substancial (não ao pé da letra) entre os novos conhecimentos e os conceitos que existem no estudante. Em contraponto à aprendizagem significativa, surge a aprendizagem mecânica que para Ausubel, Novak e Hanesian (1980) é o tipo de aprendizagem, diferentemente do processo significativo, ocorrendo quando o estudante é apresentado a um novo conhecimento, e este, por motivos variados, não o relaciona com algum conceito que já exista 
em sua mente, simplesmente, incorpora - se na sua estrutura cognitiva de maneira arbitrária e não substantiva.

A aprendizagem (significativa ou mecânica) ocorre por meio de recepção, enfatizado por Moreira (2010) como aquela em que todo o conteúdo vai ser aprendido é apresentada ao estudante na forma final ou por descoberta onde os conceitos não são fornecidos, mas deve ser "descoberto" pelo estudante antes que possa ser incorporado significativamente na sua estrutura cognitiva. No entanto, a aprendizagem por descoberta, não é necessariamente significativa, nem aprendizagem por recepção é obrigatoriamente mecânica, mas se apresentam como um continuum. Para o autor, uma posição mais defensável é de que tanto a aprendizagem receptiva ou por descoberta podem ser mecânicas ou significativas dependendo das condições que ocorre a aprendizagem.

Em ambos os casos (recepção ou descoberta) a aprendizagem significativa ocorre quando há um processo de interação no qual os conceitos mais relevantes e inclusivos (subsunçores) integram com o novo material a ser aprendido. A aprendizagem significativa é caracterizada por uma interação entre os aspectos específicos e relevantes da estrutura cognitiva e as novas informações, por meio das quais essas adquirem significado e são integradas a uma estrutura hierárquica altamente organizada de subsunçores de maneira não arbitrária e não literal.

A aprendizagem significativa deve preponderar em relação a aprendizagem de associações arbitrárias, organizacionalmente isoladas, mecânica. Para isso, algumas condições são apontadas por Ausubel, Novak e Hanesian (1980):

- A existência prévia de conceitos subsunçores, compreendido pelos autores como um conceito já existente na estrutura cognitiva, capaz de servir de ancoradouro a uma nova informação, de modo que esta adquira significado para o estudante;

- O estudante precisa ter uma disposição para aprender: se o indivíduo quiser memorizar o conteúdo arbitrária e literalmente, então a aprendizagem será mecânica. A aprendizagem significativa pressupõe que o estudante manifeste uma disposição para a aprendizagem, ou seja, disposição para se relacionar de forma não arbitrária e substantiva ao novo conhecimento;

- O conteúdo escolar a ser aprendido tem que ser potencialmente significativo, ou seja, deve estar relacionado à estrutura cognitiva do estudante, portanto, devem estar disponíveis em sua estrutura cognitiva subsunçores adequados.

A partir destas condições, Pozo (1998) cita que é preciso entender que existe uma modificação no conhecimento, balizado pela manifestação de interesse em aprender por parte do estudante e o material deverá ser potencialmente significativo. A percepção de uma aprendizagem significativa se consolida por meio de um processo que é considerado dinâmico e não unilateral, no qual os estudantes carregados de interconexões mentais e saberes se tornam peça fundamental nesse movimento de construção do conhecimento, contudo, se o estudante deseja simplesmente memorizar, o processo de aprendizagem será mecânico e sem significado.

No curso da aprendizagem significativa, Moreira (2010) enfatiza que os conceitos interagem com os novos conteúdos, servindo de base para a atribuição de novos significados que também se modificam. Essa mudança progressiva vai tornando um subsunçor mais elaborado, mais diferenciado, capaz de servir de âncora para a aquisição de novos conhecimentos, processo este que Ausubel chama de diferenciação progressiva. 
Outro processo que ocorre no encadeamento da aprendizagem significativa é o que Moreira (2010) denomina de estabelecimento de relações entre ideias, que podem ser conceitos, proposições que já se encontram na estrutura cognitiva. A existência de conceitos estáveis e com certo grau de diferenciação são relacionados com outros conceitos, passando a adquirir novos significados levando a uma reorganização da estrutura cognitiva. Essa reorganização de conceitos é conhecida por reconciliação integrativa.

A busca de indícios para a ocorrência de uma aprendizagem significativa não é uma tarefa simples. Verificar se uma aprendizagem ocorreu, segundo Ausubel, Novak e Hanesian (1980), simplesmente perguntando ao estudante os atributos de um conceito ou proposição é arriscado, haja vista a possibilidade da utilização de respostas mecanicamente memorizadas. Os autores entendem que é necessária uma compreensão no domínio dos significados que se apresentam de forma clara, precisa, diferenciados e transferíveis.

Uma sugestão apresentada por Ausubel e defendida por Moreira e Masini (2001), com objetivo de evitar uma simulação da aprendizagem significativa, é utilizar situações que sejam novas e não familiares, exigindo máxima transformação do conhecimento existente. Há diversas alternativas para verificação da ocorrência da aprendizagem significativa, como tarefas de aprendizagem sequencialmente vinculadas, servindo de apoio a etapas posteriores da atividade, a resolução de problemas bem como a utilização de mapas conceituais.

$\mathrm{Na}$ busca de indícios de uma possível aprendizagem significativa, um importante aspecto é partir dos conhecimentos que os estudantes trazem para dentro da sala de aula. "Se tivéssemos que reduzir toda a psicologia educacional a um único princípio diríamos que o fator singular mais importante que influencia a aprendizagem é aquilo que o aprendiz já sabe, descubra isso e baseie - se nisso seus ensinamentos" (AUSUBEL; NOVAK; HANESIAN, 1980, p. 137). Nesta vertente, o projeto educativo do professor deve está direcionado para 0 desenvolvimento cognitivo dos estudantes, priorizando os conhecimentos prévios, reconhecido que raramente vem marcado por estudos avançados, servindo assim de ancoragem para as novas ideias e conceitos, constituindo a base fundamental para do processo de aprendizagem.

\section{FORMAS DE APRENDIZAGEM SIGNIFICATIVA}

Durante o processo da aprendizagem significativa, a nova informação não estabelece uma espécie de elo com os elementos preexistentes da estrutura cognitiva, ao contrário, esses elos só ocorrem na aprendizagem automática. Na aprendizagem significativa, há uma mudança tanto na nova informação como no subsunçores com a qual o novo conhecimento estabelece relação, sendo que o resultado dessa interação é a assimilação de significados.

Segundo Moreira e Masini (2001) a assimilação é um processo que ocorre quando um conceito ou proposição potencialmente significativa é assimilado sob um ideia ou conceito mais inclusivo, já existente na estrutura cognitiva. A assimilação é compreendida como um relacionamento entre os aspectos relevantes, preexistentes da estrutura cognitiva, e tanto a nova informação como a preexistente são modificadas no processo. A teoria ausubeliana apresenta três formas de aprendizagem significativa, segundo a teoria da assimilação: a subordinada, superordenada e a combinatória. 


\subsection{Aprendizagem subordinada}

Segundo Ausubel, a maior incidência de aprendizagem significativa é do tipo subordinada, ou seja, a nova ideia aprendida se encontra hierarquicamente subordinada a ideia preexistente. Coll, Marchesi e Palácios (2007) comentam que a estrutura cognitiva do sujeito responde a uma organização hierárquica na qual os conceitos se conectam entre si mediante relações de subordinação, dos mais gerais aos mais específicos.

\subsection{Aprendizagem superordenada}

Nesta forma de aprendizagem significativa o novo conceito é mais geral e inclusivo que os conceitos subsunçores. Ocorre quando um conceito ou proposição mais geral do que algumas ideias já estabelecidas na estrutura cognitiva do estudante, é adquirido e passa a ser assimilado. Para Ausubel, Novak e Hanesian (1980) a nova aprendizagem será superordenada quando se aprende uma nova proposição inclusiva que condicionará o surgimento de várias ideias, ocorrendo no curso do raciocínio ou quando o material apresentando é organizado indutivamente ou envolve a síntese de ideias compostas.

\subsection{Aprendizagem combinatória}

A aprendizagem de novas proposições que não apresentam relação subordinada nem superordenada com ideias relevantes já adquiridas anteriormente na estrutura cognitiva do estudante é denominada aprendizagem combinatória. Conforme Pozo (1998) na aprendizagem significativa combinatória, a ideia nova e as ideias já estabelecidas não estão relacionadas hierarquicamente, porém se encontram no mesmo nível, não sendo nem mais específica nem mais inclusiva do que outras ideias. Ao contrário das proposições subordinadas e superordenadas, a combinatória não é relacionável a nenhuma ideia particular da estrutura cognitiva. A Figura 1 apresenta um mapa conceitual sobre alguns conceitos básicos da teoria ausubeliana. 


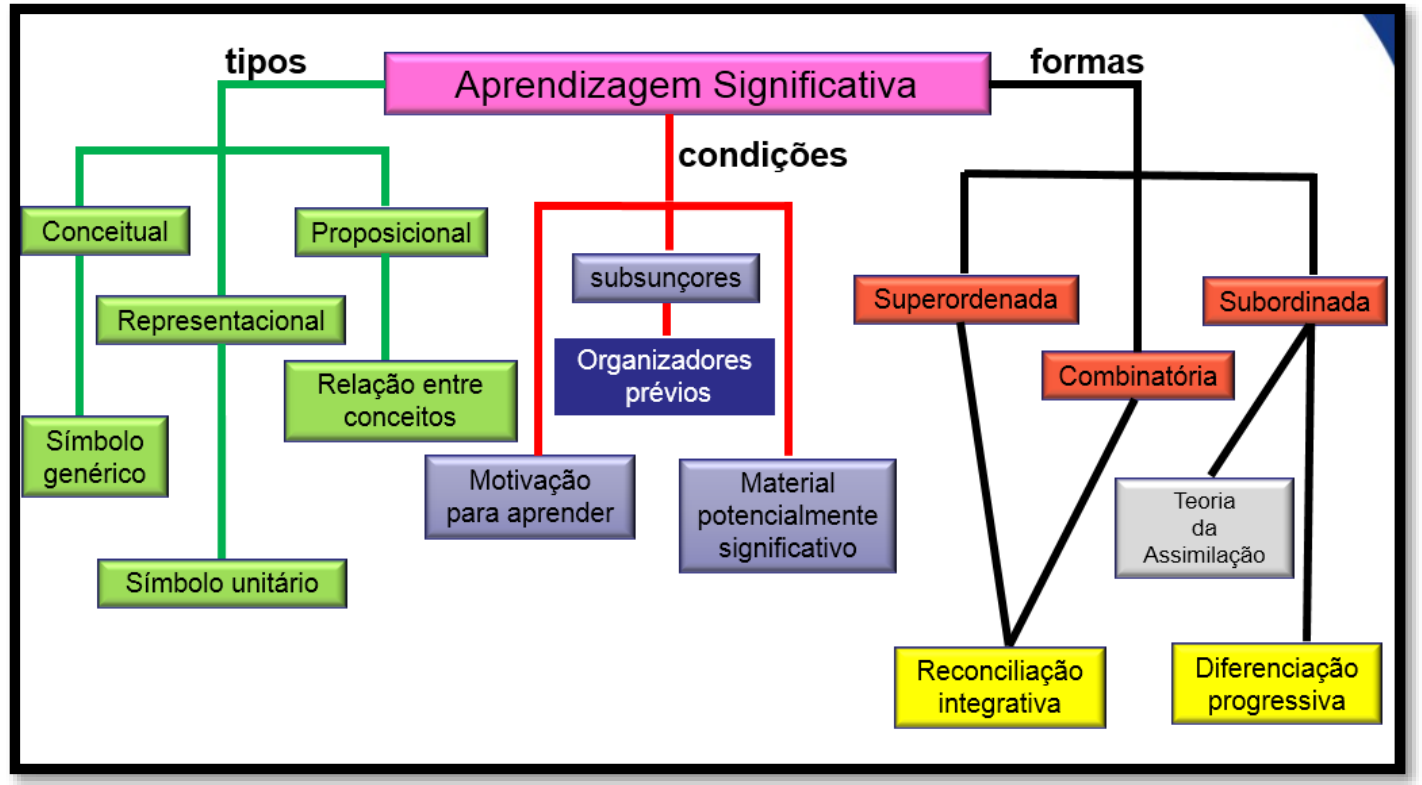

Figura 1: Conceitos pertencentes a teoria ausubeliana. Fonte: Elaborado pelo autor

\section{ASPECTOS METODOLÓGICOS}

Para o desenvolvimento da pesquisa, optamos pelo caráter participante com abordagem qualitativa. A pesquisa participante é uma pesquisa qualitativa que, segundo Bogdan e Biklen (1994) apresenta o pesquisador como seu principal instrumento para a coleta dos dados. Estes dados, quando coletados, são predominantemente descritivos e está contida em uma das metodologias da pesquisa social. É uma linha de pesquisa associada a várias formas coletivas de colaboração, com o objetivo de se pensar possíveis soluções para dificuldades e problemas que ocorrem em determinados campos de atuação, neste caso, o professor e os seus estudantes (ESTEBAN, 2010).

O investigador em uma pesquisa participante possui dois papéis, o de membro do grupo e o de pesquisador. Como membro do grupo atua normalmente e como pesquisador ele observa. O pesquisador não interfere no que o grupo faz ou deixa de fazer, isto é, não sugere ações ao grupo, porque essas ações mostrarão situações que deseja pesquisar. O pesquisador coleta dados, participa do grupo que está sendo investigado, observa as pessoas e seus comportamentos em situações de aprendizagem. Na pesquisa participante, cita Esteban (2010), deve buscar entender como os estudantes compreendem suas próprias situações e como constroem suas realidades, combinando ao mesmo tempo, a participação ativa dos estudantes, as conversas informais e as análises das atividades desenvolvidas.

Esta pesquisa aconteceu em uma turma de segunda série do Ensino Médio do turno matutino, em uma escola pública da rede estadual de ensino da cidade de Tijucas (SC), no período de 10/09 a 05/11 do ano letivo de 2012 e concluída em 2013. O instrumento de coleta de dados na pesquisa, consiste na aplicação de um questionário semiestruturado para o pré e pós-teste, contendo cinco questões fechadas e quatro questões abertas. De acordo com Gil (2010), o questionário semiestruturado é uma técnica de investigação em que os estudantes se expressam por meio de questões abertas e fechadas, sendo possível conhecer suas opiniões, sentimentos e expectativas. 
O procedimento para a análise das respostas apresentadas pelos sujeitos da pesquisa ocorreu da seguinte forma:

- Para as questões fechadas, a análise ocorreu por meio de percentuais que serviram de subsídio de comparação entre os resultados obtidos no pré e pós-teste;

- Para as questões abertas, a análise de conteúdo a posteriori foi escolhida para extrair os significados explícitos e implícitos nas respostas apresentadas pelos estudantes. Segundo Bardin (2002), a possibilidade de uma categorização com categorias a posteriori é possível a partir da análise do material. Na análise de conteúdo, o ponto de partida é a mensagem, mas devem ser consideradas as condições contextuais de seus produtores e se assenta na concepção crítica e dinâmica da linguagem. Deve ser considerado não apenas a semântica da língua, citam Puglisi e Franco (2005), mas também a interpretação do sentido que um estudante atribui às mensagens.

Após a realização do pré-teste, foi pensada a implementação de uma sequência didática, com objetivo de contribuir no processo de aprendizagem dos estudantes em relação a conceitos elementares de Geometria Esférica e Hiperbólica. Segundo Zabala (2007, p. 18) uma sequência didática é "um conjunto de atividades ordenadas, estruturadas e articuladas para a realização de certos objetivos educacionais, que têm um princípio e um fim conhecido tanto pelos professores como pelos estudantes".

A sequência didática foi estruturada em cinco módulos didáticos, a partir dos resultados obtidos no pré-teste. Cada módulo é constituído inicialmente de perguntas motivacionais, a fim de identificar as concepções dos estudantes e um conjunto de atividades. Abaixo são apresentados os módulos didáticos, o objetivo de sua execução, o tempo de sua duração e os instrumentos de coletas de dados que serviram para apresentação de resultados e discussões.

\subsection{Geometria não Euclidiana: uma visão geral}

Este módulo didático tem como objetivo apresentar uma visão geral do conceito de Geometria não Euclidiana, sua importância em outras áreas do conhecimento e sua identificação por meio de objetos encontrados na natureza. Neste módulo, foram utilizados três encontros, com aproximadamente 3 horas de duração. Os instrumentos utilizados para coleta de dados foram: as produções dos estudantes, concretizadas nas atividades desenvolvidas em sala de aula e fora dela, gravações e fotografias.

\subsection{Dos egípcios à Euclides}

Este módulo didático tem como objetivo apresentar, em síntese, a Geometria desde os egípcios até os trabalhos organizados por Euclides de Alexandria. Neste módulo, foram utilizados três encontros, com aproximadamente 3 horas de duração. Os instrumentos utilizados para coleta de dados foram: cartazes, mapas conceituais, apresentações orais com uso de projetor multimídia, maquetes e texto.

\subsection{Os postulados de Euclides}

Este módulo didático tem como objetivo apresentar os cinco postulados de Euclides e as consequências do 5o postulado para Geometria. Neste módulo, foram utilizados dois encontros, 
com aproximadamente 2 horas de duração. Os instrumentos para coleta de dados foram: texto, lista de atividades, discussões em grupo.

\subsection{Geometria Esférica}

Este módulo didático tem como objetivo apresentar conceitos elementares da Geometria Esférica e realizar comparações com a Geometria Euclidiana. Neste módulo, foram utilizados quatro encontros, com aproximadamente 4 horas de duração. Os instrumentos utilizados para coleta de dados foram: lista de exercícios, discussões em grupo, manipulação de materiais alternativos.

\subsection{Geometria Hiperbólica}

Este módulo didático tem como objetivo apresentar conceitos elementares da Geometria Hiperbólica e realizar comparações com a Geometria Euclidiana e Esférica. Neste módulo, foram utilizados cinco encontros, com aproximadamente 5 horas de duração. Os instrumentos utilizados para coleta de dados foram: lista de exercícios, manipulação de materiais alternativos, construção de uma mandala hiperbólica, construção da garrafa de Klein.

A sequência didática planejada acima buscou apresentar aos estudantes conceitos elementares de Geometria Esférica e Hiperbólica, bem como a construção, em síntese, de uma linha do tempo referente a história da Geometria. Cada módulo didático ao longo de sua execução contribuiu para a aprendizagem de conceitos geométricos, possibilitando ao estudante a realização de comparações entre os sistemas geométricos estudados em sala de aula.

\section{RECORTE DOS RESULTADOS DO PRÉ-TESTE}

Apresentaremos aqui apenas uma questão fechada e outra aberta utilizada no pré-teste.

Questão fechada 3. Ao construir um triângulo no chão, qual é a soma das medidas dos seus ângulos internos? Desenhe a alternativa escolhida.
a) 180 은
b) 270 은
c) 900
d) 100 은

O objetivo desta questão foi identificar se os estudantes conhecem uma das consequências dos postulados apresentados por Euclides de Alexandria no séc. III a.C. e estudado nos bancos escolares no ensino fundamental. Esperávamos que assinalassem a alternativa (a), porém apenas $21,43 \%$ identificaram a alternativa correta. A estratégia desses estudantes para resolver este problema partiu de uma divisão de um ângulo raso (180) em três ângulos congruentes.

Apesar da resposta correta, ficou evidente que os estudantes não apresentaram outras possibilidades para os ângulos internos de um triângulo, cuja soma é 180․ A maioria dos estudantes (64,29\%) entendeu que, ao desenhar um triângulo no chão, a soma das medidas dos ângulos internos será igual a 270으 (b) (figura 2). Este resultado mostra uma ausência de conhecimento sobre triângulos e a relação com seus ângulos internos de acordo com os ensinamentos de Geometria, possivelmente explorados no ensino fundamental. 


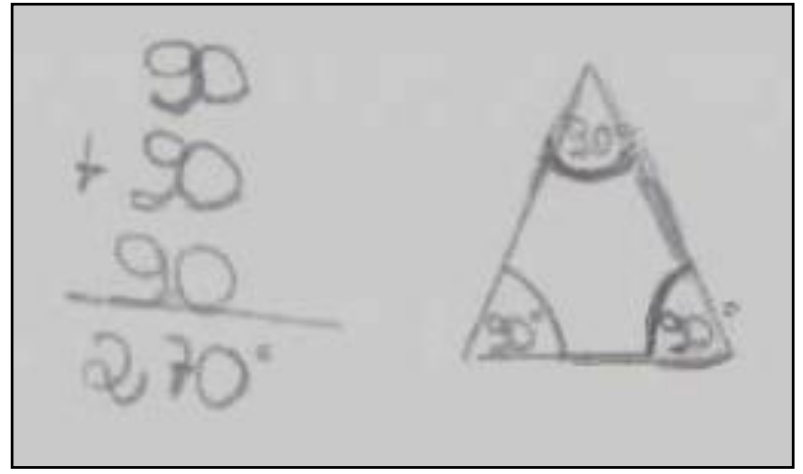

Figura 2: Protocolo do estudante I referente

à soma dos ângulos internos de um triângulo construído no chão, referente a questão 03.

A alternativa (c) foi assinalada por 14,29\%, evidenciando desconhecimento com relação a construção de triângulos e a soma das medidas dos seus ângulos internos. Ocorrem, também, indícios da falta de significado para signos, símbolos ou conceitos. Por exemplo, o estudante (I) ao representar um triângulo, demonstra fragilidade de aprendizagem conceitual sobre este símbolo em sua estrutura cognitiva. Ao colocar três ângulos internos iguais a 90으, desconsidera a definição para a soma dos ângulos internos de um triângulo euclidiano e desconhecimento do conceito de ângulo reto.

Questão aberta (2). Imagine que um caçador, resolveu sair de casa e caminhar em linha reta infinitamente.

a) Desenhe o caminho percorrido pelo caçador numa folha de papel.

b) De acordo com o caminho percorrido desenhado na folha de papel, é possível para o caçador voltar no ponto de partida?

c) Desenhe o caminho percorrido pelo caçador numa bola de isopor.

d) De acordo com o caminho percorrido desenhado na bola de isopor, é possível para o caçador voltar ao ponto de partida?

e) Anote suas conclusões.

Os estudantes em geral construíram modelos geométricos e utilizaram registros escritos (figura 3), para justificar suas respostas ao problema.

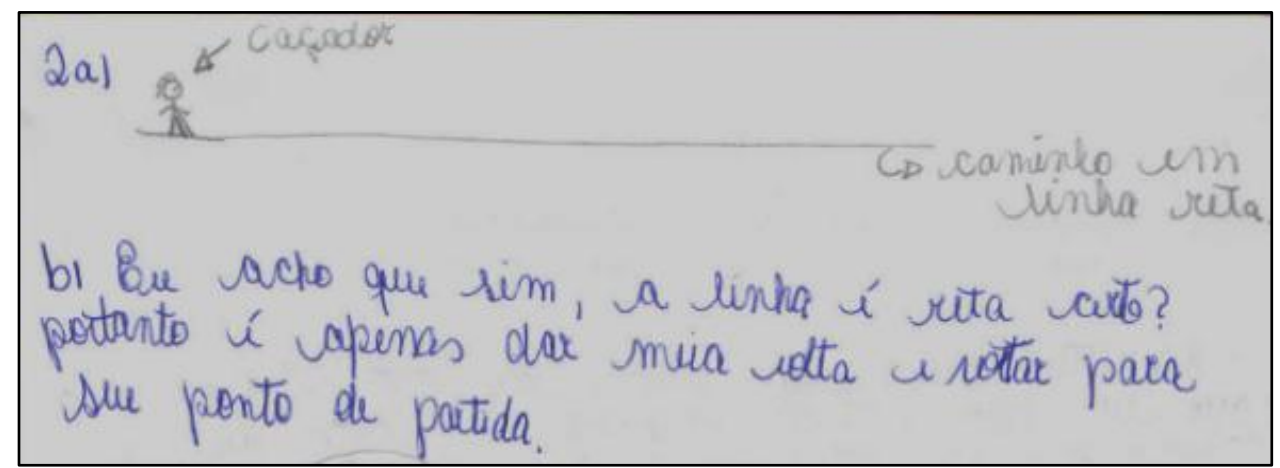

Figura 3: Protocolo apresentado pelo estudante XIV, referente à solução geométrica fornecida a questão aberta 02.

A partir dos resultados obtidos, os registros transcritos elucidaram as estratégias utilizadas na solução do problema, emergindo as categorias de subsunçores (Quadro 1):

Quadro 1: Categorias de subsunçores construídas a partir dos registros dos estudantes referentes à questão aberta 02 (pré-teste). 


\begin{tabular}{|c|c|}
\hline $\begin{array}{l}\text { É possível caminhar } \\
\text { infinitamente em linha reta e } \\
\text { retornar ao ponto de partida. } \\
\text { (visão euclidiana) }\end{array}$ & $\begin{array}{l}\text { XIV - Eu acho que ele conseguiria voltar ao ponto de partida se caminhasse em } \\
\text { linha reta, basta saber qual é o seu ponto de partida. } \\
\text { XII - Ele conseguiria, basta ir deixando marcas no caminho. } \\
\text { XI - Sim, basta ele passar pelo mar. } \\
\text { IV - Ele vai andar em linha reta e vai chegar ao ponto de partida. } \\
\text { III - Se ele for em linha reta ele saberá voltar ao ponto de partida. } \\
\text { VI - Sim, é possível se ele voltar pelo caminho correto em linha reta. } \\
\text { VIII - Minha conclusão é que se ele seguir sempre em linha reta ele fará a volta } \\
\text { na Terra e voltará ao seu destino inicial. } \\
\text { IX - Sim ele pode voltar por onde ele foi basta dar meia volta. } \\
\text { X-Sim é possível voltar de onde partiu se o caminho for em linha reta. }\end{array}$ \\
\hline $\begin{array}{l}\text { Não é possível caminhar } \\
\text { infinitamente em linha reta e } \\
\text { retornar ao ponto de partida. } \\
\text { (visão não euclidiana) }\end{array}$ & $\begin{array}{l}\text { I- Não, pois a folha é um plano e não teria como, porém no isopor é possível. } \\
\text { XIII - Na folha não tem como voltar ao ponto de partida, já na bola de isopor já } \\
\text { é possível. } \\
\text { VII - Notoriamente não será possível na folha de papel. } \\
\text { II - Na bola de isopor, ele voltará ao ponto de partida, ele vai caminhar e } \\
\text { chegará ao mesmo lugar, já na folha de papel, ele irá caminhar em linha reta } \\
\text { então não voltará no ponto de partida. } \\
V \text { - Não é possível voltar ao ponto de partida, só se eu dobrar a folha, em linha } \\
\text { reta não dá. }\end{array}$ \\
\hline
\end{tabular}

A partir dos dados coletados, esperávamos que os estudantes respondessem que o caminho percorrido pelo caçador "seria curvo", justificando o fato que a Terra tem forma arredondada, porém, dos quatorzes estudantes, nove $(64,28 \%)$ assinalaram que é possível caminhar infinitamente em linha reta e retornar ao ponto de partida, fato este relacionado com conhecimentos cristalizados de Geometria Euclidiana, onde a menor distância entre dois pontos é dada por um segmento de reta, o que aponta para uma confusão conceitual entre "reta" e "esfera".

Mesmo afirmando que seria possível retornar ao ponto de partida, os estudantes associaram o caminho percorrido pelo caçador à uma linha reta esquecendo que na superfície geométrica que vivemos, para grandes distâncias, não existem retas, mas arcos de círculos máximos (curvas). Essa ausência de aprendizagem representacional mostra que o estudante ainda memoriza modelos geométricos para aplicar na resolução de exercícios sem realizar uma reflexão acerca do problema, aspecto que Ausubel, Novak e Hanesian (1980) caracteriza como aprendizagem mecânica.

Com relação à utilização de material concreto (bola de isopor), esperávamos que construíssem círculos, consequentemente, haveria possibilidade do caçador retornar ao ponto de onde saiu, concluindo assim que a trajetória não seria uma reta. Contudo, houve estudantes que não conseguiram perceber que a trajetória seria uma curva, demonstrando uma fragilidade à aprendizagem representacional e conceitual, que segundo Ausubel, Novak e Hanesian (1980) revela a importância e a necessidade de organizar o pensamento atribuindo significado lógico e psicológico aos conhecimentos adquiridos. 


\section{RECORTE DA APLICAÇÃO DA SEQUÊNCIA DIDÁTICA}

Apresentaremos um recorte da sequência planejada, escolhendo uma atividade desenvolvida durante a pesquisa do módulo didático 4 (Geometria Esférica) e 5 (Geometria Hiperbólica).

Atividade do módulo 4

\section{Título: Andando sobre a esfera (Parte 2)}

Objetivo: Resolver as situações problema a fim de verificar os conhecimentos assimilados pelos estudantes sobre Geometria Esférica.

Forma de realização: atividade em dupla.

Materiais utilizados: calculadora, globo terrestre.

Desenvolvimento da atividade: Utilizando os conhecimentos sobre perímetro de um triângulo. resolver as atividades propostas sobre uma esfera.

1. Como você observou, unindo dois pontos distintos em uma superfície esférica, obtemos um arco de circunferência.

a) Procure medir a distância entre esses pontos. Como você mediu essa distância?

b) Há uma única distância entre esses pontos? Qual a distância entre os pólos Norte e Sul?

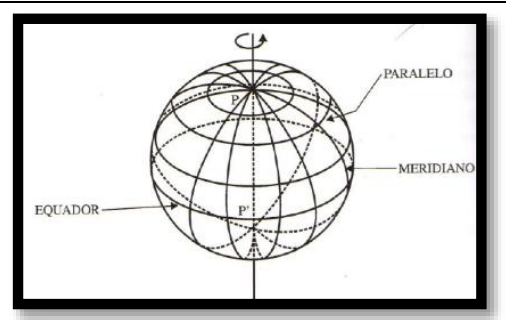

Alguns resultados obtidos e discussões: Com relação à questão 1, os estudantes, em geral, apresentaram a seguinte estratégia para a questão: a partir do centro da Terra, conhecendo aproximadamente o raio, usa-se a equação que relaciona o comprimento do arco em função do raio e seu ângulo central. As reflexões de Aleksandrov (1985), Charnay (1994), apresentadas nos PCN alertam que uma abordagem de conceitos, ideias e métodos, sob a perspectiva de resolução de problemas, ainda é bastante desconhecida da grande maioria, e quando é incorporada à prática escolar, aparece como item isolado, desenvolvido paralelamente como aplicação da aprendizagem, a partir de listagem de problemas, cuja resolução depende basicamente da escolha de técnicas ou formas de resolução memorizadas pelos estudantes.

2. Vejam a figura abaixo que mostra como 15을 de longitude no Equador corresponde a $1.669,792 \mathrm{~km}$ enquanto que à latitude de Lisboa (38. N) já só representam $1.314 \mathrm{~km}$. E muito perto do Pólo Norte (ou Sul), até mesmo 360 de longitude pode equivaler a apenas alguns centímetros.

a) Partindo dessa imagem, qual a distância da linha do Equador ao Pólo norte?

b) Se você sair do Pólo Norte e caminhar sobre qualquer meridiano até chegar a linha do Equador, em seguida girando 90 o para a esquerda ou direta e caminhando 45o, e retornando por outro meridiano até o Pólo Norte, quantos km você teria viajado?

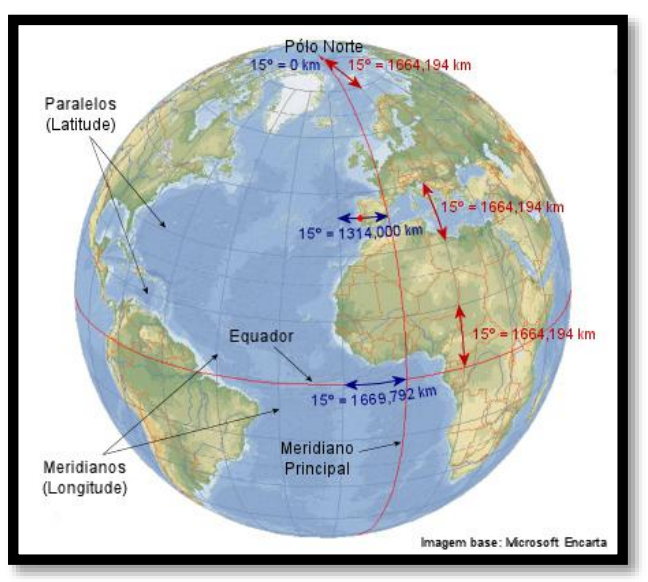


c) Os valores acima apresentados foram calculados com base nos dados adaptados no sistema WGS84 (utilizados na navegação por GPS): Raio equatorial da Terra: 6378,137 km Raio polar da Terra: $6356,752 \mathrm{~km}$. O que significa essa diferença de valores?

d) Qual e o comprimento do meridiano principal? E dos outros meridianos?

Com relação à questão 2 , os estudantes mostraram dificuldades de compreensão na relação entre a distância em graus e quilômetros entre os paralelos e meridianos, o que precisou de explicação do professor para o andamento desta questão. Coll et al. (2012) enfatiza que um fator importante que deve estar dentro do leque de preocupações de um professor durante uma atividade é se o estudante possui ou não pré-requisitos para execução do problema proposto. $\mathrm{Na}$ opinião de Mendes (2009) apoiado em Perrenoud (2002), existem escolas com grande número de estudantes apresentando dificuldades em conceitos básicos de Matemática, com falta de hábito de leitura e problemas em relacionar o conteúdo com outras áreas do conhecimento. A análise evidencia que para a questão (a), em geral, foram apresentadas respostas adequadas com os dados obtidos a partir da imagem, evidenciando além de uma aprendizagem representacional, coerência e domínio matemático.

Para questão (b), entende-se que os estudantes não estavam habituados com exercícios que envolviam conversão de graus para quilômetros como, por exemplo, caminhar "45”". Concordamos com Ausubel, Novak e Hanesian (1980) que o possível insucesso em uma atividade não significa necessariamente ausência de subsunçores ou confusões conceituais, mas, algumas vezes, dificuldades de comunicação. No processo de ensino, o professor não é um elemento neutro, é um mediador entre a atividade e o estudante, portanto a atividade é a expressão de uma perspectiva. É preciso o estudante ir ao encontro do que foi estabelecido, capaz de descobrir o significado e o objetivo da atividade. Nessa direção, o professor explicou a relação entre graus e quilômetros e os estudantes continuaram a atividade, resolvida pela maioria com êxito.

Com relação à questão (c), observa-se que os estudantes assimilaram, por meio da aprendizagem por descoberta e representacional qual é o formato do planeta Terra. No discurso dos estudantes caracteriza que "a Terra não é esférica, pois é achatada nos pólos devido à diferença entre os raios". Concordamos com Ausubel, Novak e Hanesian (1980) que percebe a mudança conceitual como uma atitude, uma motivação, um estímulo diferente daquele apresentado nas aulas tradicionais, fato da atividade ser realizada em um ambiente diferenciado do tradicional. Muitas vezes, com pequenas mudanças de atitudes ou de metodologias é possível perceber a transformação de um estado desfavorável à aprendizagem num ambiente de construção do conhecimento.

Com relação à questão (c), os estudantes apontaram que o comprimento dos meridianos seriam todos iguais. O estudante (I), por exemplo, lembrou que para calcular o comprimento de um meridiano que na Geometria Esférica é chamado de círculo máximo bastava realizar uma multiplicação entre a representação em quilômetros de 15ㅇ por vinte e quatro. Essa organização do pensamento atribuindo significado aos conceitos como "círculo máximo" e "meridiano" apresenta indícios de aprendizagem combinatória, compreendida por Ausubel, Novak e Hanesian (1980) como aquela que não privilegia relações hierárquicas entre conceitos, mas novas relações entre conceitos já existentes. 
Atividade do módulo 5

\section{Título: Garrafa de Klein}

Objetivo: Construir a garrafa de Klein a fim de identificar similaridades com a pseudoesfera, e reconhecer alguns conceitos de Geometria Hiperbólica.

Forma de realização: atividade individual.

Materiais utilizados: Garrafa Pet, mangueira corrugada, fita adesiva, tesoura, imagem da garrafa de Klein.

Desenvolvimento da atividade: Para construir a garrafa de Klein, corte a garrafa Pet em dois pontos eliminando a parte do meio da garrafa. É preciso fazer dois furos do tamanho da mangueira, no fundo da garrafa e na parte superior. Conecte a mangueira no furo principal, passando por dentro do furo superior, terminando na parte debaixo da garrafa.

Alguns resultados obtidos e discussões: O professor, ao sugerir a construção da garrafa de Klein, despertou certo interesse na turma pelo fato do desconhecimento sobre este artefato. Os estudantes argumentaram que ainda não haviam ouvido falar desse objeto e que sua construção seria um desafio. Esses comentários mostram a preocupação dos estudantes frente à atividade, porém, se mostraram predispostos para a construção, enfatizada por Novak e Gowin (1996) como condição essencial para a aprendizagem significativa. O professor apresentou uma imagem contendo a garrafa de Klein e explicou: "Esse será o objeto que vocês construirão". Após o término da construção da garrafa, conforme figura 4, o estudante (II) afirmou que "se colocarmos água na garrafa ela ficará vazia". Por outro lado, o estudante (VIII) comparou a garrafa com o modelo da pseudoesfera, entretanto argumentou que a curvatura da garrafa seria positiva devido ao seu formato.

Essa organização do pensamento, evidenciada pelo estudante (VIII), é justificada por Moreira (2010) quando este expressa que a estruturação do conhecimento na mente humana tende a seguir uma hierarquia a partir de ideias mais gerais e quando uma nova informação é submetida a determinado conceito ou representação, esta nova informação é aprendida e o conceito ou representação sofre modificações, tornando seu conhecimento prévio cada vez mais elaborado, mais diferenciado e preparado para servir de âncora a novos conhecimentos.

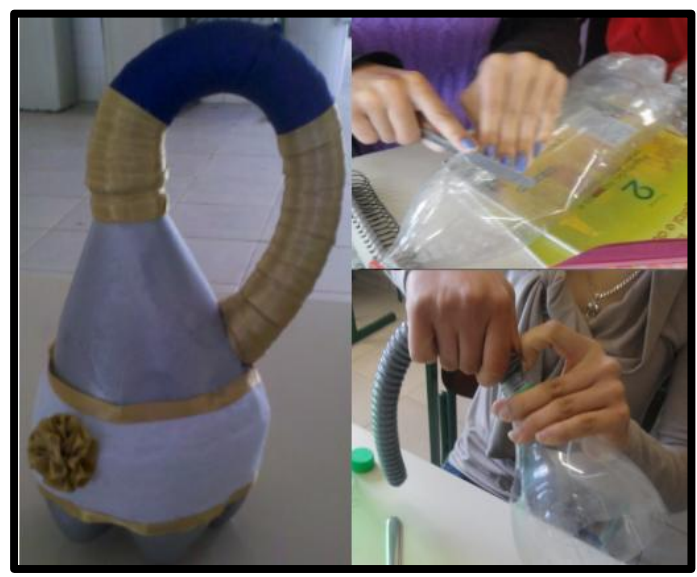

Figura 4: Garrafa de Klein construída pelos estudantes. 
Durante a execução da atividade, o estudante (X) ficou com dúvida e não soube identificar qual era o início da garrafa, "parece que ela não tem início e fim professor", apresentando mesmo de maneira inconsciente, uma propriedade da garrafa: sua não orientabilidade. O estudante (VII) comentou que no primeiro módulo aprendeu algumas ideias sobre Geometria Hiperbólica e comparou a garrafa com um vaso que se encontra na escola, cuja curvatura é negativa. $O$ professor aproveitou o momento e questionou: "Como você sabe que o vaso tem curvatura negativa?". O estudante (VIII) aproveitou e argumentou da utilização de folhas para o preenchimento da superfície com o surgimento de vincos. Nesse momento, o professor pediu a atenção dos estudantes que desenvolviam a atividade e explicou: "A noção de curvatura negativa é devido ao fato que em qualquer ponto dessa superfície, linhas se intersectam com curvaturas em sentidos opostos, porém a técnica para descobrir qual sistema geométrico pertence um determinado objeto pode ser da utilização de folhas e a observação de vincos".

No fim da construção da garrafa, os estudantes (X), (VI), (IV), (VII) e (XI) solicitaram ao professor um resumo sobre a Geometria Hiperbólica e Esférica, prontamente atendida. A análise evidencia que, quando o professor trabalha com materiais potencialmente significativos, proporciona, segundo Ausubel, Novak e Hanesian (1980), uma motivação para a aprendizagem e não uma passividade promovida por problemas do tipo "siga o modelo". Em geral, esta atividade conseguiu despertar a motivação tão necessária nos estudantes para sua realização, bem como comparações com outros sistemas geométricos (Esférico e Euclidiano). No que diz respeito às limitações da atividade, há um reconhecimento que, em função dos objetivos propostos pelo professor-pesquisador, houve necessidade de alguns acertos com relação ao tempo de duração, recortes, ajustes e mudanças, como por exemplo, a continuidade da atividade em casa. Mas isto não atrapalhou o processo de ensino e aprendizagem sobre o tema Geometria Hiperbólica.

\section{RECORTE DOS RESULTADOS DO PÓS-TESTE}

Apresentaremos a questão fechada 3 e a questão aberta 2 utilizada no pré-teste, afim de comparação em termos percentuais e comportamento na categoria de análise.

Questão fechada 3. Ao construir um triângulo no chão, qual é a soma das medidas dos seus ângulos internos? Desenhe a alternativa escolhida.
a) 180 o
b) 270 은
c) 90 은
d) 100 은

Os resultados mostram que $78,57 \%$ dos estudantes assinalaram a alternativa (a), apontando que a soma dos ângulos internos de um triângulo construído no chão seria igual a dois ângulos retos. Praticamente $7 \%$ dos estudantes compreendem ainda que a soma seria três ângulos retos (b) e quase $7 \%$ expressaram como sendo um ângulo reto e um estudante não assinalou. No gráfico 1, apresentamos uma comparação entre as alternativas escolhidas pelos estudantes no pré e pós-teste, a fim de servir como subsídio para análise.

Gráfico 1: Comparação entre o número de estudantes que escolheram as alternativas para questão 3 no pré e pósteste. 


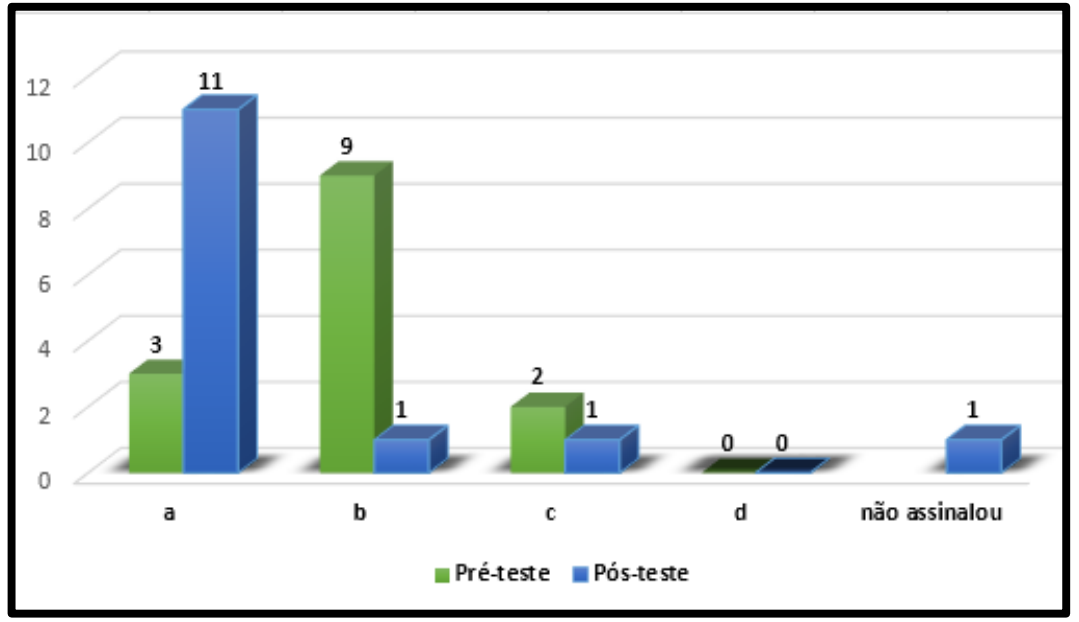

Os resultados evidenciam uma assimilação no conceito de triângulo euclidiano e uma conexão com a soma dos seus ângulos internos. Foi detectada uma aprendizagem conceitual, representacional e proposicional por grande parte da turma, expressada pelas transcrições, como por exemplo, dos estudantes (I), (VII) e (XI) que escreveram: "apenas vale para superfície plana, que é a Geometria de Euclides (euclidiana), porém se a soma for maior do que 180 estaremos tratando de uma Geometria Esférica, se for menor do que dois retos é uma Geometria Hiperbólica e sua curvatura é negativa". Já o estudante (VI) preferiu não assinalar, justificando seu posicionamento frente à questão (figura 5).

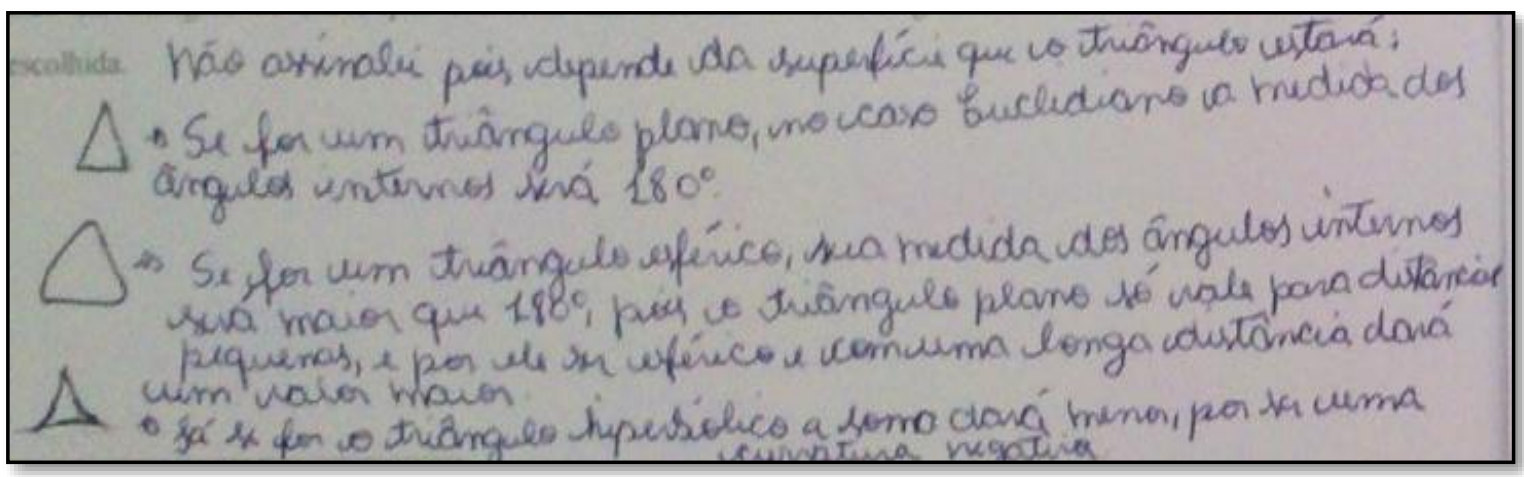

Figura 5: Protocolo do estudante VI, referente à questão 3 do pós-teste.

De acordo com Ausubel, Novak e Hanesian (1980), é preciso atenção na elaboração de questões de avaliação, pois normalmente solicita-se apenas uma repetição de informações ou ideias aprendidas. Nessa direção, não conseguimos por meio de questões fechadas, identificar avanços na aprendizagem, muito menos como os estudantes construíram significados na estrutura cognitiva, porém, ao permitir por meio de desenho o modelo geométrico adequado para o triângulo, conforme seu sistema geométrico, é possível perceber que os estudantes aprenderam como representar adequadamente cada triângulo.

Questão aberta (2). Imagine que um caçador, resolveu sair de casa e caminhar em linha reta infinitamente.

a) Desenhe o caminho percorrido pelo caçador numa folha de papel.

b) De acordo com o caminho percorrido desenhado na folha de papel, é possível para o caçador voltar no ponto de partida?

c) Desenhe o caminho percorrido pelo caçador numa bola de isopor.

d) De acordo com o caminho percorrido desenhado na bola de isopor, é possível para o caçador 
voltar ao ponto de partida?

e) Anote suas conclusões.

A partir dos resultados obtidos, os registros transcritos elucidaram as estratégias utilizadas na solução do problema, emergindo as categorias de análise (Quadro 2):

Quadro 2: Categorias de análise construídas a partir dos registros dos estudantes referentes à questão aberta 02 (pós-teste).

\begin{tabular}{|c|c|}
\hline Categorias & Unidade de registro \\
\hline $\begin{array}{l}\text { Entendeu que é possivel caminhar } \\
\text { infinitamente em linha reta e } \\
\text { retornar ao ponto de partida. } \\
\text { (visão euclidiana) }\end{array}$ & $\begin{array}{l}\text { III - Se for numa figura plana ele conseguirá, agora na esférica não, por } \\
\text { causa da distância que o caçador pode estar. } \\
\text { VIII - O caçador chegará ao ponto de partida, basta retornar pelo } \\
\text { caminho que traçou. }\end{array}$ \\
\hline $\begin{array}{l}\text { Entendeu que não é possível } \\
\text { caminhar infinitamente em linha } \\
\text { reta e retornar ao ponto de } \\
\text { partida. } \\
\text { (visão não euclidiana) }\end{array}$ & $\begin{array}{l}\text { II - Não é possível, pois ele caminhará em uma reta infinita e não chegará } \\
\text { ao seu ponto de partida, pois uma reta infinita não tem fim. } \\
\text { XI - Na superfície plana não é impossível, já na superfície esférica é } \\
\text { possível voltar ao ponto de origem. } \\
\text { XIV - É possível o caçador voltar ao ponto de partida, só que ele andará } \\
\text { não em linha reta, mas, sobre uma curva, pois a geometria da Terra é } \\
\text { esférica. } \\
\text { V - Não, pois os pontos de partida e fim não irão se encontrar isso só } \\
\text { aconteceria se o caminho fosse sobre a esfera. } \\
X \text { - Bom, não tem como ele andar em uma linha reta e voltar, terá que } \\
\text { fazer curvas. } \\
\text { IX - Ele não conseguirá dar uma volta completa, ele terá que andar em } \\
\text { círculo, ai conseguirá voltar. } \\
\text { XII - Claro que não conseguiria retornar, se andasse em uma superfície } \\
\text { plana, somente encima de uma bola de isopor ou encima da Terra. } \\
\text { VI - Não é possível ele voltar ao ponto de partida por linha reta, pois não } \\
\text { vivemos no plano, mas em uma esfera. } \\
\text { VII - No plano (folha) ele não conseguiria, mas, no globo conseguiria. } \\
\text { XIII - Não é possível voltar se andar em linha reta infinitamente, não vai } \\
\text { conseguir. } \\
\text { I- Percebi que em uma superfície plana nunca chegaremos de onde } \\
\text { saímos, mas, na superfície esférica que é onde vivemos, conseguimos } \\
\text { chegar. } \\
\text { IV- Não é possível voltar ao ponto de partida, andando sob um caminho } \\
\text { reto, sempre andaríamos, iríamos cansar e não voltaríamos, não tem } \\
\text { como. }\end{array}$ \\
\hline
\end{tabular}

Dos estudantes participantes, dois $(14,28 \%)$ responderam que é possível o caçador voltar ao ponto de partida, se caminhar infinitamente sobre uma reta. Esse posicionamento por parte desses estudantes evidencia ainda uma visão euclidiana para compreender fenômenos, mesmo após a realização da sequência didática. Ausubel, Novak e Hanesian (1980) asseveram que o estudante precisa ter uma disposição para a aprendizagem significativa. Não é suficiente existir conhecimentos prévios relevantes e apresentar um material potencialmente significativo se o estudante não dispuser de vontade para aprender significativamente. Nesse sentido, é necessário que o estudante se disponha a relacionar os novos conhecimentos com aqueles já existentes em sua estrutura cognitiva de forma consciente e não trivial. 
Os autores citam que toda prática educativa que não faça com que o estudante assimile o significado da tarefa de aprendizagem, falha em lhe proporcionar um sentimento de confiança nas suas capacidades e em nada contribui para incrementar a sua sensação de domínio sobre os acontecimentos. Assim, o surgimento de respostas com concepções euclidianas pode ser indicativo de fragilidades no processo de ensino e ausência de motivação por parte dos estudantes para relacionar os conhecimentos adquiridos com as ideias relevantes existentes em sua estrutura cognitiva.

Por outro lado, é preciso ressaltar que doze estudantes $(85,72 \%)$ apontaram a impossibilidade de o caçador retornar ao ponto de partida por meio de uma trajetória retilínea. A maioria, ainda incrementou a utilização de uma superfície esférica como possível solução. É importante apontar a ocorrência de uma mudança conceitual, bem como, uma possível reorganização dos conhecimentos adquiridos na estrutura cognitiva de cada estudante. Essa mudança, comentado por Moreira e Greca (2003), não supõe a ideia de substituição dos conhecimentos prévios do estudante, mas sim, uma proposta de significados na linha da aprendizagem significativa, na descriminação e desenvolvimento/enriquecimento conceitual, ou seja, uma evolução conceitual.

Nessa direção, os referidos conhecimentos adquiridos possibilitou que os subsunçores originais de cada estudante fossem modificados ao final do processo de assimilação. Essa modificação está baseada no princípio que, tanto o subsunçor como o novo conhecimento, fossem assimilados e incorporados à estrutura cognitiva do estudante de modo não arbitrário e não literal. Desse modo, o posicionamento dos doze estudantes, ao comparar e atribuir significado a conceitos como "reta", "curva", "trajetória", "infinito", mesmo de maneira não formal e esperada pelo professor, evidenciam possíveis mudanças nos significados, tornando-se mais elaborados, ricos e diferenciados.

Ao compreender o que the foi ensinado, o estudante consegue justificar suas respostas com suas próprias palavras o significado do material aprendido. Assim, na elaboração de desenhos, o estudante (VI), por exemplo, conseguiu elaborar um texto explicativo apresentando elementos essenciais para compreensão do tema, como "linha reta", "plano", "meridiano", "curvas" e "pólos". Com relação ao texto, o estudante utilizou de palavras de ligação, como, "possível", "voltará" e "encontram" construindo proposições válidas.

Todo esse processo de compreensão de determinado conteúdo ocorre de modo dinâmico, visto que cada estudante é agente ativo e intervirá no texto a partir das informações dadas, processando e atribuindo significados. Devido à sua dimensão idiossincrática, Ausubel, Novak e Hanesian (1980) defendem que o texto não possui significado interno, ou seja, encontrase pronto e acabado. Assim, quando o estudante transmite uma mensagem, raramente estão explicitadas todas as suas ideias, mas apenas são apresentados alguns recortes baseados em seus conhecimentos prévios e suas aprendizagens.

\section{CONSIDERAÇÕES FINAIS}

O enfoque dessa pesquisa referiu-se a inserção da Geometria Esférica e Hiperbólica no ensino de Matemática da Educação Básica, conteúdo este que apontou, entre outros fatores, a inquietação de alguns pesquisadores em função das ingerências relatadas por diversos 
professores da rede pública na abordagem deste tema. Alguns professores relataram que conteúdos referentes ao ensino de Geometria Esférica e Hiperbólica, raramente são apresentados em cursos de formação continuada ou que estão praticamente ausentes nos livros didáticos, representados apenas por ilustrações superficiais, bem como, apontaram sua indicação pelos Parâmetros Curriculares Nacionais (PCN), os quais apresentam a importância do ensino de outras geometrias.

A partir dessas problemáticas, esta pesquisa foi orientada pela seguinte questão: Como explorar os conceitos de Geometria Esférica e Hiperbólica no Ensino Médio, a fim de desenvolver a compreensão nos estudantes para a pluralidade de modelos geométricos no espaço em que vivem? Com o intuito de responder a questão, estabeleceu-se como objetivo principal analisar o desenvolvimento de uma sequência didática e suas contribuições para a aprendizagem de conceitos elementares de Geometria Esférica e Hiperbólica junto aos estudantes do Ensino Médio. Nesse sentido, para a realização dessa dissertação, foram elaboradas diferentes atividades didáticas para a abordagem de conceitos pertencentes à Geometria Esférica e Hiperbólica em sala de aula.

Para verificar a viabilidade da abordagem, as atividades didáticas foram aplicadas em sala de aula para uma turma de 14 estudantes da 2a série do Ensino Médio de uma escola estadual da cidade de Tijucas em Santa Catarina. Na aplicação, foram analisadas a aprendizagem dos estudantes frente às atividades que tratavam de conceitos elementares de Geometria Esférica e Hiperbólica. As questões utilizadas no pré-teste, referentes a conteúdos de Geometria Euclidiana, Esférica e Hiperbólica foram fundamentais para o delineamento acerca da elaboração de atividades no ensino de Geometria Esférica e Hiperbólica. A partir dos resultados do pré-teste, foi possível identificar que os estudantes possuíam em sua estrutura cognitiva, alguns conceitos (subsunçores) sobre Geometria e se utilizaram desses para resolver as questões propostas.

Percebeu-se que, durante a sequência didática, a metodologia escolhida pela apresentação do tema, por meio de perguntas motivacionais e realização de atividades contribuíram para que se desenvolvessem de maneira satisfatória a construção de conceitos elementares de Geometria Esférica e Hiperbólica. Observamos que os textos, os vídeos, os mapas conceituais construídos pelos estudantes, as maquetes e as demais atividades colaboraram para que os resultados do pós-teste tenham tido maior porcentagem na qualidade de acertos, se comparado com as questões do pré-teste. Esse resultado veio ao encontro do que Ausubel, Novak e Hanesian (1980) argumentam sobre a importância de atividades diferenciadas como, a produção de maquetes, a construção de mapas conceituais, apresentações, bem como a resolução de atividades sequenciadas, enquanto contribuições para ocorrência da aprendizagem significativa.

A Teoria da Aprendizagem Significativa de Ausubel e seus colaboradores (1980), as orientações de Novak e Gowin (1996) e Moreira (2010) nos auxiliaram na compreensão dos processos de aprendizagem, dos conceitos científicos, e principalmente, na relação entre professor e estudante em sala de aula. Foram identificados durante a sequência didática, momentos de ocorrência de aprendizagem significativa do tipo representacional, conceitual e proposicional, bem como indícios de aprendizagem superordenada, subordinada e combinatória por parte dos estudantes nas atividades propostas, contribuindo para que o professor compreendesse como os conceitos foram assimilados pela estrutura cognitiva e de que maneira estes se encontram organizados. 
A sequência didática foi planejada a partir dos resultados obtidos no pré-teste, evidenciando a necessidade do primeiro módulo ter característica de organizador prévio correlativo, que segundo Ausubel, Novak e Hanesian (1980) é uma estratégia de manipular a estrutura cognitiva do estudante acerca de conhecimentos referentes a Geometria Esférica e Hiperbólica, conceitos considerados mais gerais e inclusivos e menos sensíveis a assimilação obliteradora. A partir desse primeiro módulo, os demais tiveram a intenção de apresentar e diferenciar conceitos e propriedades pertencentes a Geometria Euclidiana da Geometria Esférica e Hiperbólica, com o intuito de colaborar junto ao estudante, para compreensão de outros modelos geométricos existentes e de contribuir para a construção e reorganização de sua estrutura hierárquica referente aos conceitos sobre Geometria Esférica e Hiperbólica.

Assim, consideramos que uma maneira para promover uma aprendizagem significativa é considerar na sequência didática a exploração de ideias prévias que os estudantes possuem, a apresentação de situações problematizadoras, a inserção de recursos didáticos, enquanto organizadores prévios para manipular a estrutura cognitiva na ausência de subsunçores, bem como, proporcionar momentos de diálogo entre os pares. Pode-se dizer que a sequência didática foi construída procurando facilitar a aprendizagem significativa através da utilização de materiais potencialmente significativos, isto é, relacionáveis sob a natureza lógica e psicológica que explicitamente buscam promover a diferenciação progressiva e a reconciliação integrativa.

Em resposta à questão que norteou esta pesquisa, a abordagem por meio da sequência didática referente a apresentação de conceitos elementares de Geometria Esférica e Hiperbólica a partir de perguntas motivacionais e realização de atividades práticas, como construção de mapas conceituais, registro e identificação de objetos no ambiente escolar, resolução de problemas sequenciados, apresentações e debates, construção de modelos não euclidianos, construção de maquetes, uso de vídeos em consonância com outras áreas do conhecimento, contribuíram de maneira significativa para que o estudante desenvolva a compreensão da existência de outros modelos geométricos no espaço em que vivem. As perguntas motivacionais e as atividades práticas foram importantes durante o processo de aprendizagem, pois contribuíram na organização dos significados que os estudantes atribuíam aos conceitos abordados.

Foram identificados, também, momentos de motivação e interatividade no decorrer da pesquisa, em busca da construção nos significados dos conceitos de Geometria Esférica e Hiperbólica. As atividades práticas promoveram a motivação e a interatividade tanto entre os estudantes, como entre professor com os estudantes. O professor pode somente apresentar ideias de modo significativo, no entanto, a tarefa de organizar novas ideias num quadro de referência pessoal só pode ser realizada pelo estudante, ideia enfatizada por Novak e Gowin (1996), em que compreendem que a participação do professor durante todo o procedimento de construção é de grande importância.

Quanto às contribuições que nossa pesquisa possa vir a trazer para a comunidade científica da Educação Matemática, acreditamos ser esta no campo da metodologia de ensino, mais precisamente, das estratégias didáticas, objetivando o processo de ensino e aprendizagem de Geometria Esférica e Hiperbólica. A pesquisa como um todo, isto é, a discussão na íntegra das outras questões do pré-teste e pós-teste, os resultados obtidos e discussões de outras atividades desenvolvidas na sequência didática, podem ser encontradas em Brum (2013). 


\section{REFERÊNCIAS BIBLIOGRÁFICAS}

1. ALEKSANDROV, A. D. La matemática: su contenido, métodos y significado. Madri: Alianza Universidad, 1985.

2. AUSUBEL, D. P; NOVAK, J. D.; HANESIAN, H. Psicologia Educacional. Rio de Janeiro: Interamericana, 1980.

3. ALVES, S. Geometria Não Euclidiana. São Paulo: IME-USP: material para oficina; Semana da Licenciatura, 2008.

4. BARDIN, L. A análise de conteúdo. Lisboa: Edições 70, 2002.

5. BOGDAN, R.; BIKLEN, S. Investigação qualitativa em educação: uma introdução à teoria e aos métodos. Porto: Porto Editora, 1994.

6. BONGIOVANI, V. De Euclides às geometrias não euclidianas. Revista Iberoamericana de Educación Matemática. São Paulo, v.1, n. 22, p. 37-51, 2010.

7. BOYER, C. B. História da Matemática. 2a . ed. São Paulo: Blücher, 2009

8. BRASIL. Secretaria de Educação Fundamental. Parâmetros curriculares nacionais: matemática. Brasília: MEC/SEF, 1998.

9. CABARITI, E. A geometria hiperbólica na formação docente: possibilidades de uma proposta com o auxílio do cabri-géomètre. III Seminário Internacional de Pesquisa em Educação Matemática, São Paulo, 2006.

10. CARVAlho, M. A. S.; CARVALHO, A. M. F. T. C. O ensino de geometria não euclidiana na educação básica. XIII Conferência Interamericana de Educação Matemática, Recife, 2011.

11. CEDREZ, A. J. P. Construcción, necessidad e intuición de essência em geometria. Scientia \& Studia. São Paulo, v. 7, n. 4, p. 595-617, 2012.

12. CHARNAY, R. Aprender por meio de la resolucion de problemas. Didáctica de matemáticas. Aportes y reflexiones. Argentina: Paidós Educador, 1994.

13. COLL, C., et al. O Construtivismo na Sala de Aula. São Paulo: Ática, 2012.

14. COLL, C.; MARCHESI, A.; PALACIOS, J. Desenvolvimento psicológico e educação: psicologia da educação escolar. 2a. ed. Porto Alegre: Artmed, 2007.

15. COURANT, R.; ROBBINS, H. O que é matemática? Uma abordagem elementar de métodos e conceitos. Rio de Janeiro: Ciência Moderna, 2000.

16. COUTINHO, L. Convite às Geometrias Não Euclidianas. 2ạ. ed. Rio de Janeiro: Interciência, 2001.

17. ESTEBAN, M. P. S. Pesquisa qualitativa em educação: fundamentos e tradições. Porto Alegre: Artmed, 2010.

18. EVES, H. Introdução à história da Matemática. São Paulo: Unicamp, 2008.

19. GIL, A. C. Como elaborar projetos de pesquisa. São Paulo: Atlas, 2010.

20. KALEFF, A. M. Desenvolvimento de Atividades Introdutórias ao Estudo das Geometrias não Euclidianas: Atividades Interdisciplinares para Sala de Aula e Museus Interativos. Congresso Brasileiro de Extensão Universitária, n. 2, Belo Horizonte, 2004. 
21. LEIVAS, J. C. P. Educação geométrica: reflexões sobre ensino e aprendizagem em geometria. Revista SBEM-RS, Porto Alegre, n. 13, v.1, p. 9-16, 2012.

22. MARTOS, Z. G. Geometrias não euclidianas: uma proposta metodológica para o ensino de Geometria no Ensino Fundamental. 143f. Dissertação (Mestrado em Educação Matemática) Instituto de Geociências e Ciências exatas, Universidade Estadual Paulista, Rio Claro, 2012.

23. MENDES, I. A. Matemática e investigação em sala de aula: tecendo redes cognitivas na aprendizagem. São Paulo: Livraria da Física, 2009.

24. MLODINOW, L. A janela de Euclides: a história da geometria, das linhas paralelas ao hiperespaço. São Paulo: Geração, 2010.

25. MOREIRA, M. A. Mapas conceituais e aprendizagem significativa. São Paulo: Centauro, 2010.

26. MOREIRA, M. A.; GRECA, I. M. Mudança conceitual: análise crítica e propostas à luz da teoria da aprendizagem significativa. Ciência e Educação, Bauru, v. 9, n. 2, p. 301-315, 2003.

27. MOREIRA, M. A.; MASINI, E. F. S. Aprendizagem significativa: A teoria de David Ausubel. São Paulo: Centauro, 2001.

28. NOVAK, J. D.; GOWIN, B. D. Aprender a Aprender. Lisboa: Plátano Edições Técnicas, 1996.

29. PERRENOUD, P. As Competências para Ensinar no Século XXI: a formação dos professores e o desafio da avaliação. Porto Alegre: Artmed, 2002.

30. POZO, J. I. Teorias cognitivas da aprendizagem. 3a. ed. São Paulo: Artes Medicas, 1998.

31. PUGLISI, M. L.; FRANCO, B. Análise de conteúdo. 2å. ed. Brasília: Líber Livro, 2005.

32. STRUIK, D. J. História Concisa das Matemáticas. São Paulo: Gradiva, 1997.

33. VOGELMANN, E. P. A arte de ensinar e construir o conhecimento. São Paulo: Saraiva, 2011.

34. ZABALA, A. A prática educativa: como ensinar. Porto Alegre: Artmed, 2007. 